\title{
Dielectric relaxation and freezing effect in $\mathrm{Sn}_{2} \mathbf{P}_{2} \mathbf{S}_{6}$
}

\author{
M.M.Maior, Sh.B.Molnar, V.T.Vrabel, M.I.Gurzan, S.F.Motrja, \\ Yu.M.Vysochanskii \\ Institute for Solid State Physics and Chemistry, \\ Uzhgorod National University, Uzhgorod, Ukraine
}

Received October 24, 2002, in final form April 2, 2003

The temperature-frequency studies of dielectric susceptibility in $\mathrm{Sn}_{2} \mathrm{P}_{2} \mathrm{~S}_{6}$, $\mathrm{Sn}_{2} \mathrm{P}_{2} \mathrm{Se}_{6},\left(\mathrm{~Pb}_{y} \mathrm{Sn}_{1-y}\right)_{2} \mathrm{P}_{2} \mathrm{Se}_{6}$ and crystals at low temperatures are reported. The freezing relaxation dynamics has been observed in a temperature-frequency dependence of the dielectric properties in the crystals which are in a polydomain ferroelectric state as well as in the crystals $\left(\mathrm{Pb}_{y} \mathrm{Sn}_{1-y}\right)_{2} \mathrm{P}_{2} \mathrm{Se}_{6}$ with $y>0.4$ which at low temperatures are in the incommensurate phase. The nature of the effect and its interrelation with dynamics of ferroelectric domain walls and incommensurate structure is discussed.

Key words: domain walls, freezing effect, dielectric properties

PACS: $77.84 . D, 77.80 . B h$

\section{Introduction}

Much research was devoted to the investigation of low temperature properties in the crystals of $\mathrm{Sn}_{2} \mathrm{P}_{2} \mathrm{~S}_{6}$ type. However, some phenomena observed at low temperatures in these materials are not clearly understood. In particular, this is an effect of a sharp decrease of the dielectric constant with lowering temperatures below a certain value. It must be mentioned that a similar behavior is typical of many ferroelectrics: $\mathrm{KDP}[1], \mathrm{PbTiO}_{3}$ [2], SBN [2]. In most cases it was attributed to a freezing of domain walls dynamics. This phenomenon was very intensively studied in the crystals of KDP family (see references in the paper [1]). An analysis of the relaxation dispersion observed in polydomain TGS crystals far below $T_{\mathrm{c}}$ in the ferroelectric phase [1] reveals that the domain freezing effect occurs in this material as well. Therefore, it is obvious that the freezing of the domain walls motion is a rather characteristic property for polydomain ferroelectrics.

Some anomalies on temperature dependence of the dielectric constant and the pyroelectric response in $\mathrm{Sn}_{2} \mathrm{P}_{2} \mathrm{~S}_{6}$ at $T<80 \mathrm{~K}$ were reported in the paper [3]. It was interpreted as a "glass-like behavior". Besides the pronounced dielectric dispersion 
was found in $\mathrm{Sn}_{2} \mathrm{P}_{2} \mathrm{~S}_{6}$ at temperatures around $60 \mathrm{~K}$ [4]. The origin of the dispersion was related to the structural disorder.

A sharp decrease of the dielectric constant below approximately $50 \mathrm{~K}$ in the incommensurate phase in $\left(\mathrm{Pb}_{y} \mathrm{Sn}_{1-y}\right)_{2} \mathrm{P}_{2} \mathrm{Se}_{6}$ solid solutions with $y>0.4$ accompanied with a pronounced dielectric dispersion with a broad spectrum of relaxation times is related to the freezing of the relaxation dynamics of the incommensurate modulation wave [5].

This paper presents the comparison analysis of dielectric properties of the crystals with stable incommensurate and ferroelectric phases at low temperatures.

\section{Experimental}

The crystals investigated were grown using vapor transport technique [6].

The samples with the shape of platelets perpendicular to the polar [100] direction were used in the experiment. The dielectric measurements were performed with E714 and BM560 LCR-meters in the temperature range 4.2-300 K using a liquid helium cryostat (UTREKS).

In order to get a single domain state, the samples were poled under the electric field of $2 \mathrm{kV} / \mathrm{cm}$ on cooling from the temperatures above the ferroelectric phase transition.

It seems likely that the dielectric measurements in the paper [4] were carried out with polydomain sample of $\mathrm{Sn}_{2} \mathrm{P}_{2} \mathrm{~S}_{6}$. Besides, the sample used in the experiment was oriented along [011] the non-polar direction. To some extent, this makes quantitative comparison with the results obtained for the polar direction difficult.

\section{Results and discussion}

Figure 1 shows temperature dependence of the complex dielectric constant $\varepsilon^{\prime}$ and $\varepsilon^{\prime \prime}$ at various frequencies for a polydomain $\mathrm{Sn}_{2} \mathrm{P}_{2} \mathrm{~S}_{6}$ crystal in the temperature range 80-260 K. In consistence with earlier report [4] we have also observed, in the frequency range measured, the dielectric dispersion accompanied by the peaks of $\varepsilon^{\prime \prime}(T)$ shifted to higher temperatures with the increasing frequency. It should be pointed out that in the single domain sample, in these temperature and frequency ranges, no anomalies were observed. In this case, both $\varepsilon^{\prime}$ and $\varepsilon^{\prime \prime}$ take much lower values.

These facts unambiguously indicate that the dispersion observed is of the domain nature. In the given temperature range, a pronounced relaxation of the dielectric properties with time is observed. It should be stressed that $\varepsilon^{\prime \prime}(T)$ peaks become less pronounced with the lowering of the measuring voltage and below certain field they become quite indistinguishable (figure 1).

This is a demonstration of a strong nonlinear dielectric effect. However, the dielectric responses in the given temperature range have a reversible character up to the voltage of the measuring field of the order of $100 \mathrm{~V} / \mathrm{cm}$. 


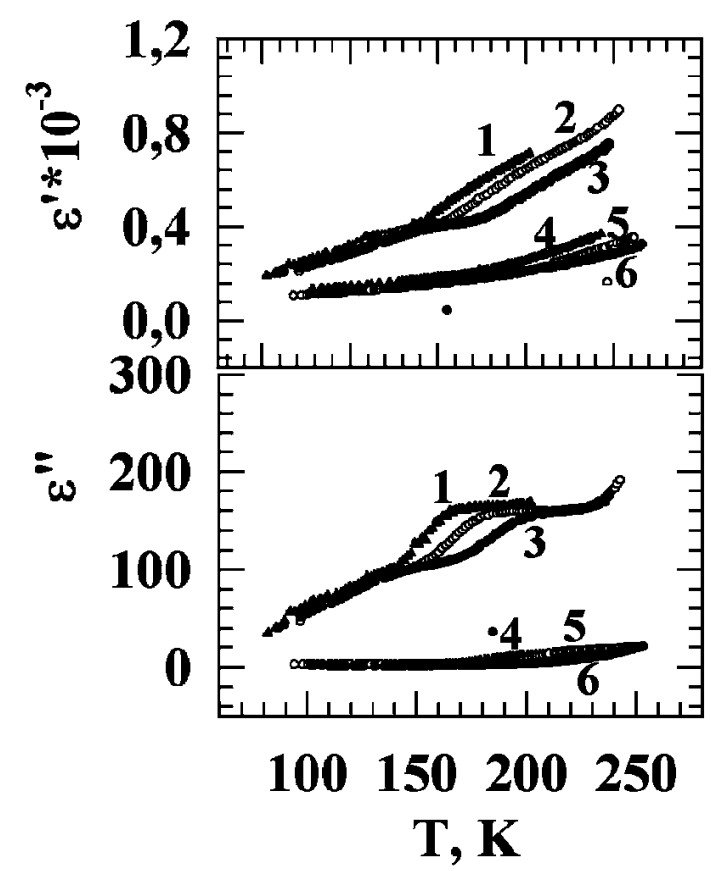

Figure 1. Temperature dependence of $\varepsilon^{\prime}$ and $\varepsilon^{\prime \prime}$ for $\mathrm{Sn}_{2} \mathrm{P}_{2} \mathrm{~S}_{6}$ crystal at various frequencies and measuring electric fields: $1,4-100 \mathrm{~Hz}, 2,5-1 \mathrm{kHz}, 3,6-10 \mathrm{kHz}$; $1,2,3-10 \mathrm{~V} / \mathrm{cm}, 3,4,5-1 \mathrm{~V} / \mathrm{cm}$.

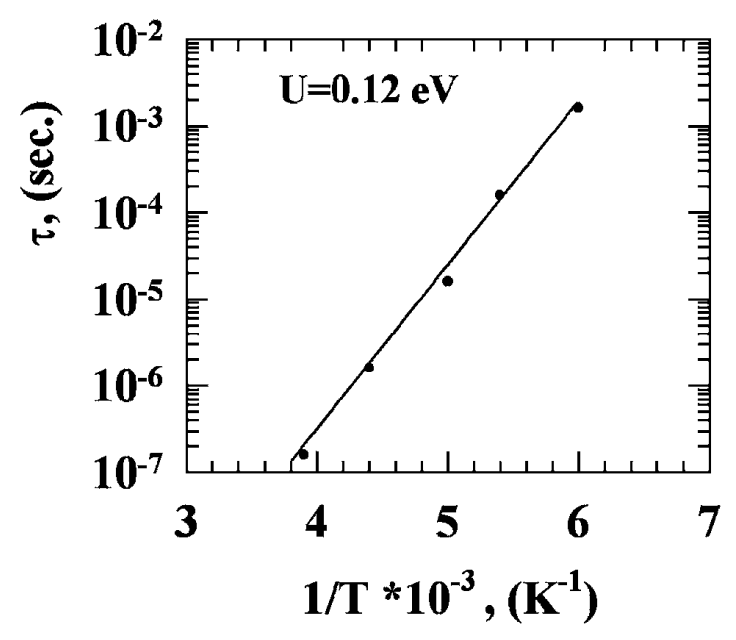

Figure 2. Relaxation time as a function of reciprocal temperature for the dielectric dispersion observed in $\mathrm{Sn}_{2} \mathrm{P}_{2} \mathrm{~S}_{6}$ in the temperature range $150-250 \mathrm{~K}$.
These facts indicate that the dielectric dispersion observed is caused by the relaxation dynamics of the domain walls. The temperature dependence of the leading relaxation time determined from the temperature position of the peaks of $\varepsilon^{\prime \prime}$ is well described by the Arrhenius law (figure 2). The activation energy obtained from the fitting of the experimental data by the Arrhenius relation:

$$
\tau=\tau_{0} \exp \left(-\frac{E_{\mathrm{a}}}{k_{\mathrm{b}} T}\right),
$$

is $E_{\mathrm{a}}=0.12 \mathrm{eV}$.

As to the dielectric dispersion found in [4] at lower temperatures (around $60 \mathrm{~K}$ ), it is rather obvious that it also has a domain nature, since in the single domain samples it is not detected. The real and imaginary part of the dielectric constant in this temperature range are frequency independent: both $\varepsilon^{\prime}$ and $\varepsilon^{\prime \prime}$ show a weak and smooth temperature behavior $\left(\varepsilon^{\prime \prime}(T)\right.$ dependence is not presented in figure 3). The weak maximum on $\varepsilon^{\prime \prime}(T)$ with a peak temperature depending on the frequency is also observed in polydomain samples of $\mathrm{Sn}_{2} \mathrm{P}_{2} \mathrm{Se}_{6}$ at temperature around $40 \mathrm{~K}$. At the same time, the dielectric constant in a single domain sample takes much lower value and the dielectric dispersion is not found.

In $\left(\mathrm{Pb}_{y} \mathrm{Sn}_{1-y}\right)_{2} \mathrm{P}_{2} \mathrm{Se}_{6}$ solid solutions with $y>0.4$, the incommensurate phase is stable up to very low temperatures. The sharp decrease of $\varepsilon^{\prime}$ below $50 \mathrm{~K}$ in these crystals is accompanied by a low frequency dielectric dispersion with characteristic maximum on $\varepsilon^{\prime \prime}(T)$ shifted up to higher temperatures with the increasing frequency (figure 4). In the paper [5] it was concluded that the temperature dependence of the leading relaxation time determined from the temperature of the $\varepsilon^{\prime \prime}$ peak obeys the Arrhenius 
law. However, when an analysis is performed without taking into account the $\varepsilon^{\prime \prime}(T)$ dependence measured at frequencies below $50 \mathrm{~Hz}$, at which the accuracy of measurements is rather poor, then $\tau$ shows a temperature behavior according to the Fogel-Fulcher relation (figure 5), as should be expected in the case of the freezing effect:

$$
\tau=\tau_{0} \exp \left(\frac{E_{\mathrm{a}}}{T-T_{\mathrm{f}}}\right)
$$

with a freezing temperature $T_{\mathrm{f}}=15 \mathrm{~K}$. It is worth noting that the freezing effect occurs approximately in the same temperature range in solid solutions with various compositions. Moreover, the solid solutions of $\left(\mathrm{Pb}_{y} \mathrm{Sn}_{1-y}\right)_{2} \mathrm{P}_{2} \mathrm{Se}_{6}$ with $y<0.4$ which at low temperatures are in the ferroelectric state exhibit a kink on $\varepsilon^{\prime}(\mathrm{T})$ and $\varepsilon^{\prime \prime}(T)$ with a more steep decrease of $\varepsilon^{\prime}$ and $\varepsilon^{\prime \prime}$ at the same temperatures (figure 6 ). The curve 3 corresponds to the single domain sample. It is obvious that the domain wall contribution to the dielectric response decreases with the lowering temperature.

It should be mentioned that at the temperatures much as in the case of incommensurate phase, the temperature hysteresis dies out and the ferroelectric polarization becomes irreversible. These facts indicate that at such temperatures the freezing of the domain structure occurs.

It is well known that the pinning of the domain walls can substantially effect the dielectric behavior of polydomain ferroelectrics. Thus to gain an insight into the mechanism of the freezing effect the pinning of the domain wall by the defects should be taken into consideration.

In theory two types of pinning are distinguished: a weak collective pinning when the domain walls are pinned on the fluctuations in the density of defects, and a strong pinning when the domain walls are pinned by many separate defects. 


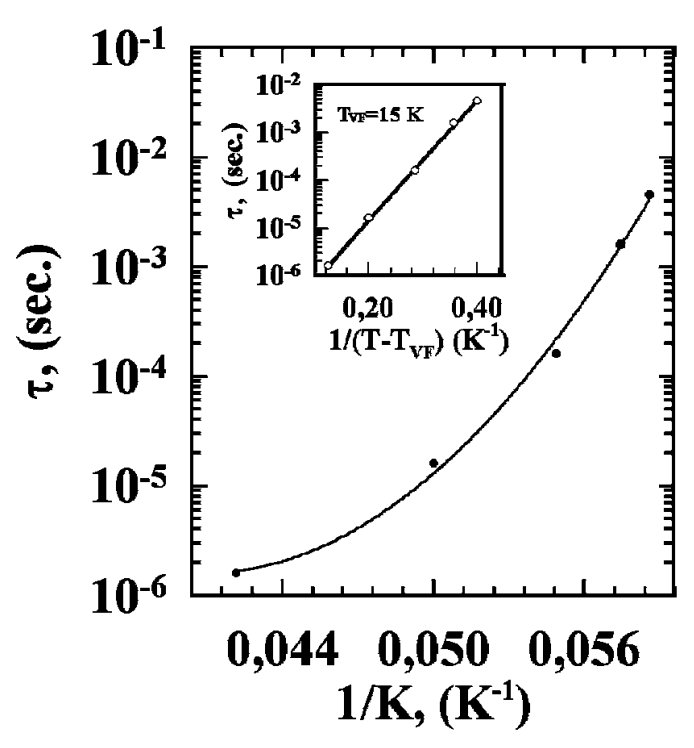

Figure 5. Relaxation time related to the dielectric dispersion in $\left(\mathrm{Pb}_{0.4} \mathrm{Sn}_{0.6}\right)_{2} \mathrm{P}_{2} \mathrm{Se}_{6}$ as a function of reciprocal temperature. Insert: relaxation time as a function of $1 /\left(T-T_{\mathrm{VF}}\right)$ with $T_{\mathrm{VF}}=15 \mathrm{~K}$.

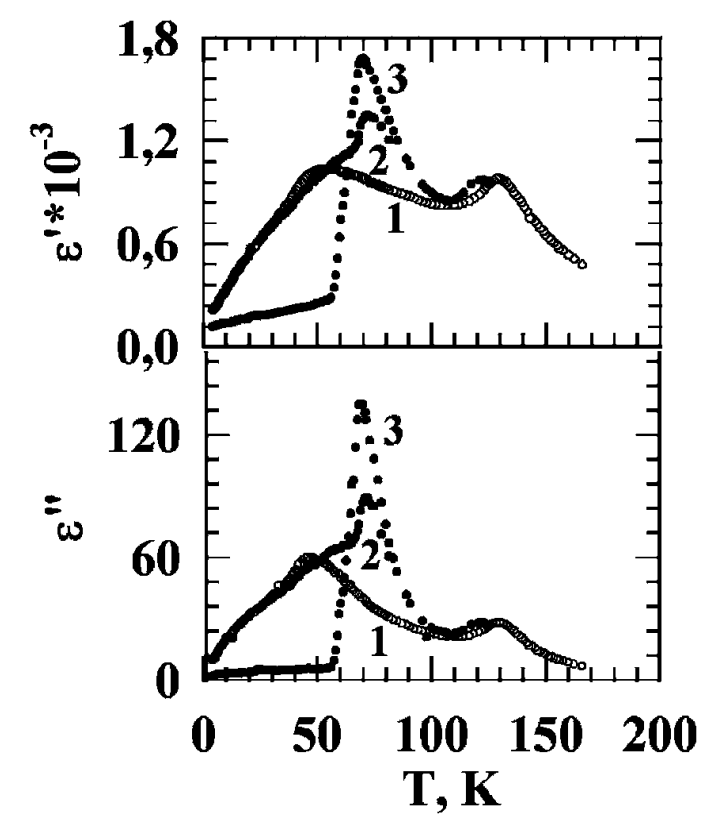

Figure 6. Dielectric constant $\varepsilon^{\prime}$ and dissipation $\varepsilon^{\prime \prime}$ for $\left(\mathrm{Pb}_{0.35} \mathrm{Sn}_{0.65}\right)_{2} \mathrm{P}_{2} \mathrm{Se}_{6}$ mixed crystals versus temperature upon cooling (1) and heating (2) for polydomain sample. Curves 3 correspond to single domain sample.
More distinctly the freezing effect is observed in the dielectric behavior of the crystals of $\left(\mathrm{Pb}_{y} \mathrm{Sn}_{1-y}\right)_{2} \mathrm{P}_{2} \mathrm{Se}_{6}$ with $y>$ 0.4 in the incommensurate phase (figure 6).

The incommensurate wave of modulation interacting with the defects has many different metastable configuration states between which at high temperature it fluctuates in activation way moving over the potential barriers. As temperature decreases, the relaxation time of the incommensurate modulation increases and at a certain temperature becomes infinite. This temperature is defined as a freezing temperature below which the incommensurate modulation is frozen in certain configuration states. Temperature independence of the wave vector of incommensurate modulation [7] and hysteresisless temperature behavior of the dielectric constant [5] observed experimentally at low temperatures in these crystals is a consequence of the freezing effect.

The incommensurate modulation in the crystal studied can be considered as a consequence of broad domain walls. The high defect density caused by the substitutions in the cation sublattice at a large width of walls provide the conditions for the weak collective pinning. On the other hand, the freezing effect can be considered as the relaxation of the incommensurate modulation when the pinning energy becomes so high that thermal fluctuation of the walls becomes negligible.

The fact that the freezing temperature $T_{\mathrm{f}}$ is not changed markedly with the change of the composition of the solid solutions argues in favor of the suggestion that the defects induced by substitutions in the cation sublattice are involved in the weak collective pinning. 
A more steep decrease in $\varepsilon^{\prime}$ and $\varepsilon^{\prime \prime}$ at similar temperatures in polydomain samples of $\left(\mathrm{Pb}_{y} \mathrm{Sn}_{1-y}\right)_{2} \mathrm{P}_{2} \mathrm{Se}_{6}$ with such a content of $\mathrm{Pb}$ and $\mathrm{Sn}(y<0.4)$ when the ferroelectric phase is stable at low temperatures argues in favor of the freezing effect in the system of the ferroelectric domain walls (figure 6). However, judging from the temperature frequency dependence of $\varepsilon^{\prime}$ and $\varepsilon^{\prime \prime}$ one can conclude that, in addition to the domain wall contribution which is frozen out, there is also the contribution given by the domain walls but which persists below the freezing temperature.

The dielectric response of the domain walls or the interfaces pinned by the defects was thoroughly studied in the paper [8]. Having many metastable configurations, the domain walls fluctuate under the effect of external electric field between their different energy minima separated by energy barriers giving relaxation contribution to the dielectric constant. The relaxation spectra of the dielectric response of disordered ferroelectrics resembles the Debye relaxation with a broad distribution of relaxation times [8]. Besides, it has been shown that for the domain walls pinned by the defects there exists a length scale on which the domain wall is free. The dielectric contribution coming from that length scale is frequency independent. However, the characteristic length on which the domain wall is free depends on frequency and temperature. This is reflected in a weak temperature dependence and in logarithmic frequency dependence of $\varepsilon$ in the low frequency range [8].

Comparing the temperature behavior of the dielectric response at various frequencies in $\left(\mathrm{Pb}_{y} \mathrm{Sn}_{1-y}\right)_{2} \mathrm{P}_{2} \mathrm{Se}_{6}$ in the incommensurate and the in the ferroelectric phase with the prediction of the theory [8] one can conclude that:

- the dominant contribution to the dielectric response in the incommensurate phase at low temperatures comes from the relaxation dynamics of the incommensurate modulation pinned by the defects. With the lowering temperature, the relaxation dynamics is frozen out;

- sharp decrease of $\varepsilon^{\prime}$ and $\varepsilon^{\prime \prime}$ below $50 \mathrm{~K}$ in $\left(\mathrm{Pb}_{y} \mathrm{Sn}_{1-y}\right)_{2} \mathrm{P}_{2} \mathrm{Se}_{6}$ with $y<0.4$ in the ferroelectric phase is an indication of the freezing of ferroelectric domain walls pinned by the defects. This is supported by the fact that below $50 \mathrm{~K}$, the domain becomes irreversible up to very high electric fields. The main contribution of the domain walls to the dielectric constant comes from the length scale on which the domain walls are free;

- the characteristic length scale for the incommensurate modulation and the ferroelectric domain walls in $\left(\mathrm{Pb}_{y} \mathrm{Sn}_{1-y}\right)_{2} \mathrm{P}_{2} \mathrm{Se}_{6}$ crystals seems to be of the same order since the freezing effect is observed approximately at the same temperatures both in the ferroelectric and in the incommensurate phases.

Since the phase transition into the ferroelectric phase in $\mathrm{Sn}_{2} \mathrm{P}_{2} \mathrm{~S}_{6}$ and $\mathrm{Sn}_{2} \mathrm{P}_{2} \mathrm{Se}_{6}$ occurs at relatively high temperatures (335 K and $193 \mathrm{~K}$, respectively) their domain walls at low temperatures must be thinner comparing to the mixed crystals with low temperature phase transition. Small width of domain walls at a low defect density provides conditions for a strong pinning. Thus, a higher value of the freezing temperature in these crystals as compared with the solid solutions very likely resulted 
from the change in the pinning character. It is well known that an increase in the pinning force should shift the freezing temperature up to higher temperatures.

\title{
References
}

1. Huang Y.N., Li X., Wang Y.N., Shen H.M., Zhang Z.F., Fang C.S., Zhuo S.H., Fung P.C.W. // Phys. Rev. B., 1997, vol. 55, p. 16159-16166.

2. Hegenbarth E. - In: Proceeding of $6^{\text {th }}$ International Symposium "High-Purity Materials in Science and Technology", Dresden, 1985, p. 94-103.

3. Bravina S.L., Morozovsky N.V., Kadashchuk A.K., Manzhra V.S. // Ferroelectrics, 1997, vol. 201, No. 1-4, p. 197-201.

4. Iwata M., Miyashita A., Ishibashi Y., Morija K., Jano S. // J. Phys. Soc. Japan, 1998, vol. 67 , p. 499-511.

5. Maior M.M., Wiegers S.A.J., Rasing Th., Eijt S.W.H., Penning F.C., Vysochanskii Yu.M., Motrja S.F., Van Kempen H. // Ferroelectrics, 1998, vol. 202, No. 1-4, p. $139-148$.

6. Gurzan M.I. Ph.D. Thesis, Uzhgorod State University, 1983.

7. Hlinka J., Cyrrat R., Quikichini M., Gregora I., Vysochanskii Yu.M. - In: Proceeding of $10^{\text {th }}$ International Meeting on Ferroelectricity, Madrid, 2001, p. 98.

8. Natterman T., Shapir Y., Vilfan I. // Phys. Rev. B., 1990, vol. 42, p. 8577-8584.

\section{Діелектрична релаксація і ефект заморожування в кристалах типу $\mathrm{Sn}_{2} \mathbf{P}_{2} \mathrm{~S}_{6}$}

\author{
М.М.Майор, Ш.Б.Молнар, В.Т.Врабель, М.І.Гурзан, \\ С.Ф.Мотря, Юл.М.Височанський \\ Ужгородський Національний Університет, Ужгород
}

Отримано 24 жовтня 2002 р., в остаточному вигляді - 2 квітня 2003 p.

В роботі приводяться температурно-частотні дослідження діелектричної проникливості при низьких температурах в кристалах в $\mathrm{Sn}_{2} \mathrm{P}_{2} \mathrm{~S}_{6}, \mathrm{Sn}_{2} \mathrm{P}_{2} \mathrm{Se}_{6},\left(\mathrm{~Pb}_{y} \mathrm{Sn}_{1-y}\right)_{2} \mathrm{P}_{2} \mathrm{Se}_{6}$. Спостерігалося заморожування релаксаційної динаміки на температурно-частотних залежностях діелектричних властивостей, як в кристалах які при низьких температурах знаходяться в сегнетоелектричному полідоменному стані, так і в кристалах $\left(\left(\mathrm{Pb}_{y} \mathrm{Sn}_{1-y}\right)_{2} \mathrm{P}_{2} \mathrm{Se}_{6}\right.$ з $\left.y>0.4\right)$, які при низьких температурах знаходяться в неспівмірній фазі. Обговорюється природа ефекту у взаємозв'язку з сегнетоелектричними доменами і неспівмірною структурою.

Ключові слова: доменні стінки, ефект заморожування, діелектричні властивості

PACS: $77.84 . D, 77.80 . B h$ 
